\title{
Black esophagus: acute esophageal necrosis complicating diabetic ketoacidosis
}

\author{
Hourmazd Haghbayan MD, Avijeet K. Sarker MD, Eric A. Coomes MD
}

Cite as: CMAJ 2018 September 4;190:E1049. doi: 10.1503/cmaj.180378

A 55-year-old woman with poorly controlled diabetes mellitus presented with three days of anorexia and coffeeground emesis in the context of noncompliance to insulin therapy. She denied caustic ingestion and was hemodynamically stable on presentation. Blood tests showed hyperglycemia (glucose $25.4 \mathrm{mmol} / \mathrm{L})$, anion-gap metabolic acidosis ( $\mathrm{pH} 7.21)$ and ketosis ( $\beta$-hydroxybutyric acid $12.99 \mathrm{mmol} / \mathrm{L}$ ). Diabetic ketoacidosis was managed in a medical step-up unit with potassium supplementation, intravenous fluid resuscitation and intravenous insulin infusion, followed by transition to subcutaneous insulin. For suspected upper gastrointestinal bleed, she received an intravenous proton pump inhibitor (PPI) infusion and was given nothing by mouth.

Subsequent esophagogastroduodenoscopy showed circumferential black mucosa in the distal esophagus, immediately proximal to the gastroesophageal junction (Figure 1, A and B), sparing the gastric and duodenal mucosae. This endoscopic appearance is consistent with acute esophageal necrosis. After achievement of good glycemic control and six days of PPI therapy, repeat endoscopy showed substantial resolution of the mucosal necrosis, with residual inflammation and patchy ulcers (Figure 1, C and D). Following discharge, gastric acid suppression with an oral PPI was continued; however, the patient was subsequently lost to follow-up.

Acute esophageal necrosis, or "black esophagus," is a rare clinical entity that may complicate acute hyperglycemic states, such as diabetic ketoacidosis, and has also been reported in association with critical illness, shock, sepsis, ischemia and malignancy. ${ }^{1}$ Preceding caustic ingestion must be excluded. The hallmark image on endoscopy is diffuse, friable, dark mucosal discoloration of the distal esophagus, terminating sharply before the gastroesophageal junction, and sparing the stomach, duodenum and proximal esophagus. ${ }^{1}$ Acute esophageal necrosis may arise from hypoperfusion, corrosive injury and decreased mucosal repair secondary to physiologic stress. ${ }^{1}$ Treatment is supportive, with esophageal rest, gastric acid suppression and correction of any reversible underlying conditions. ${ }^{2}$ Underlying illness severity portends poor prognosis. ${ }^{3}$ Potential complications include esophageal perforation, superinfection and strictures. ${ }^{1}$

\section{References}

1. Gurvits GE. Black esophagus: acute esophageal necrosis syndrome. World J Gastroenterol 2010;16:3219-25.

2. Gurvits GE, Cherian K, Shami MN, et al. Black esophagus: new insights and multicenter international experience in 2014. Dig Dis Sci 2015;60:444-53.

3. Ben Soussan E, Savoye G, Hochain P, et al. Acute esophageal necrosis: a 1-year prospective study. Gastrointest Endosc 2002;56:213-7.
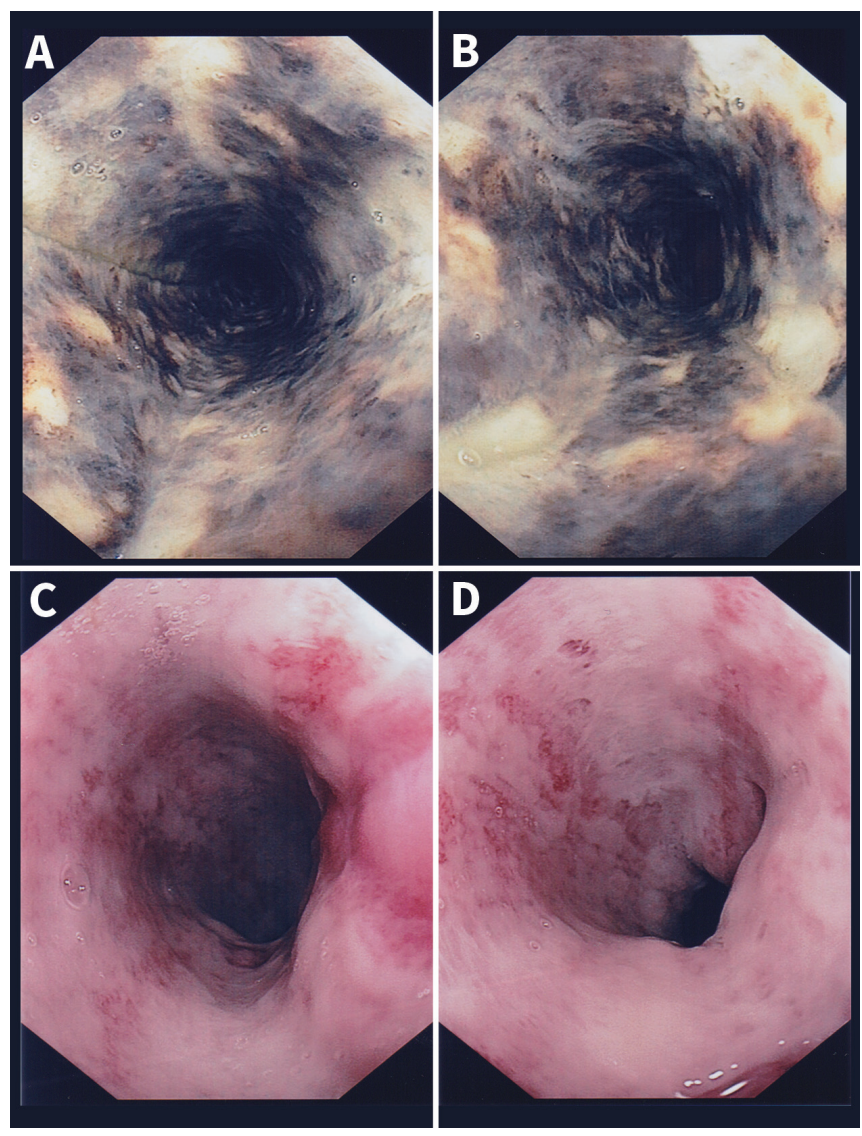

Figure 1: Endoscopic images of the mid to distal esophagus in a 55-yearold woman showing dark mucosal discoloration consistent with acute esophageal necrosis (A, B) and its subsequent resolution following correction of diabetic ketoacidosis and gastric acid suppression (C, D).

Competing interests: None declared.

This article has been peer reviewed.

The authors have obtained patient consent.

Affiliations: Department of Medicine (Haghbayan, Sarker, Coomes), University of Toronto, Toronto, Ont.; Department of Social and Preventive Medicine (Haghbayan), Université Laval, Québec, Que.

Correspondence to: Hourmazd Haghbayan, hourmazd.haghbayan @mail.utoronto.ca 